\title{
NRAS NM_002524.4:C.37G>C
}

National Cancer Institute

\section{Source}

National Cancer Institute. NRAS NM 002524.4:C.37G>C. NCI Thesaurus. Code C155674.

A nucleotide substitution at position 37 of the coding sequence of the NRAS gene where guanine has been mutated to cytosine. 